Psychological Medicine, 1990, 20, 763-765

Printed in Great Britain

EDITORIAL

\title{
Barbiturate-assisted interviews in modern clinical practice ${ }^{1}$
}

It has long been observed that information can be released by drugs and that a man off-guard may reveal things that he wants to hide. 'In vino veritas', as the Romans said. Psychiatrists, over the years, have used many agents in attempts to elucidate the concealed contents of their patients' minds; the list has ranged from alcohol, amphetamines and lysergic acid diethylamide (LSD) to the barbiturates and benzodiazepines (Naples \& Hackett, 1978). The most popular has proved to be sodium amylobarbitone (sodium amytal), first synthesized by Schonle \& Moment in 1923. It became the drug of choice not only because of its rapid induction time but also because it was reputed to release speech and thought rather than action. In recent years, however, the approach has largely fallen from common use. This editorial examines the possibility that a valuable investigative tool has also been discarded.

\section{A PLACE IN HISTORY}

In order to understand current attitudes to barbiturate-assisted interviews it is helpful to set the technique in its historical context. As early as 1861 Griesinger had described remarkable improvements in psychotic states following deep sleep induced by anaesthetic and narcotic substances (Griesinger, 1867). In 1922 Kläsi outlined a standardized narcosis therapy using somnifene (diethylamine-allylisopropyl-barbiturate), but it was William J. Bleckwenn who first reported on the use of amylobarbitone in psychiatry in 1930 . Bleckwenn $(1930 a, b)$ decided to experiment with amylobarbitone to promote sleep in psychotic patients with states of mental excitement, after the drug's successful use in surgical anaesthesia. His aim was to prevent the rapid physical decline leading to death from terminal pneumonia or cardiac failure that was so often seen in these cases. Bleckwenn treated his patients by inducing prolonged narcosis - a condition similar to general anaesthesia but not as profound - with repeated injections over a number of days. He observed that 'in a few cases there was a lucid interval for 1 to 2 minutes before the patient went to sleep'. During this short interval, the patient was rational and had complete insight into his condition. A year later Erich Lindemann experimented with sub-anaesthetic doses in both 'normal and abnormal individuals' (Lindemann, 1932). He described 'a desire to communicate...[and] a willingness to speak about very personal problems'. The amylobarbitone interview had arrived.

Although narcosis therapies were linked with biological approaches to psychiatry, historically barbiturate-assisted interviews also have roots in dynamic psychiatry. In 1895 Breuer \& Freud published Studies in Hysteria, extending Janet's work on the cathartic cure for neuroses and heralding the development of Freud's psychoanalysis. The 'talking cure' was quickly taken up and used by enthusiasts of drug-assisted interviewing in the treatment of a wide range of disorders (Ellenberger, 1970). New terms appeared: narco-analysis, which combined narcosis, hypnosis and analytic techniques; narco-synthesis; narco-catharsis and others (Horsley, 1936; Grinker, 1944; Hoch, 1946).

With the advent of World War II the use of the amylobarbitone interview increased dramatically. In particular, the technique was widely used to facilitate 'abreaction' - the free expression and release of previously repressed emotion - most notably in the treatment of post-traumatic disorders (Sargant \& Slater, 1940). The enthusiasm continued after 1945 and there was little hesitation in advising the use of amylobarbitone interviews in civilian practice. The techniques used varied from

' Address for correspondence: Dr M. Patrick, The Maudsley Hospital, Denmark Hill, London SE5 8AZ. 
prolonged narcosis to 'narco-hypno-analysis', and the indications were protean. In 1949 Tilkin wrote that 'the future of narcosynthesis is infinite and the possibilities endless'.

Nevertheless, by the early 1960s the use of the technique was in decline. The reasons for this are complex but the recognition of barbiturate dependence certainly played a part. In addition, the introduction of chlorpromazine in 1952, and subsequently of the tricyclic antidepressants, dramatically altered the practice of the majority of psychiatrists. The mixture of biological and dynamic approaches within the one technique led to uncertainty about the underlying intentions, indications and manner of administration of the interview. The vogue for using hallucinogenic drugs such as LSD and mescaline can only have contributed to the misgivings.

\section{A PLACE IN MODERN PRACTICE?}

In recent years some authors have tried to revive interest in the amylobarbitone interview, properly making the distinction between therapeutic and diagnostic applications (Perry \& Jacobs, 1982). Most therapeutic applications, however, are reliant on a dynamic approach to treatment. Psychotherapeutic practice involves establishing a relationship in which trust, talk and understanding help a person to accept difficult issues. Many would consider that for this the patient needs to be fully conscious and cooperative (Hadfield, 1942; Brown \& Pedder, 1979). Furthermore, the status of abreaction within psychotherapy has been discussed over many years; although the results may be dramatic, it has been argued that alone it is insufficient to produce lasting change (Strachey, 1934). The psychiatrist may end up striving with the patient for a magic cure, passing over the real areas of difficulty (Bronner, 1955). In the treatment of hysteria, Lambert \& Rees (1944) found that intravenous barbiturates produced no significantly better results than general psychiatric treatment or hypnosis; the only advantage obtained was economy of time, in particular with hysterical amnesias. Even then, several authors have questioned the mode of action. Lewis, in 1941, suggested that 'the pharmacological effect is probably trifling in comparison with the suggestive value of the method'. For all these reasons it could be argued that acceptable therapeutic indications are few.

Is there then a place for drug-assisted diagnostic interviews in modern clinical practice? In 1979 Dysken et al. conducted a double-blind, randomized, and placebo-controlled trial of the sodium amylobarbitone interview. They addressed the question of whether or not the drug facilitated the recovery of new and clinically useful information. The results indicated that although the interview was moderately useful in eliciting new information, there was no difference in efficacy between barbiturate and placebo (saline) interviews. Research into the neuropsychiatric indications of barbiturate-assisted interviews has yielded more positive findings. Evidence suggests that the technique may be useful as a sensitive probe of cognitive functioning, and in the diagnosis of organic brain syndromes. Weinstein et al. (1954) found that intravenous amylobarbitone highlighted subtle cognitive deficits in patients with central nervous system pathology, while controls showed no similar deterioration. On serial testing the response to amylobarbitone was found to parallel the progression of pathology. More recent reports have indicated a possible role for the interview in the differentiation of dementia from 'pseudodementia' (Snow \& Wells, 1981), and in the investigation of 'confusional states' (Ward et al. 1978). In these studies patients with underlying organic pathology exhibited a temporary deterioration in cognitive functioning in response to amylobarbitone. Those with 'functional' deficits improved. A degree of caution does need to be exercised, however. In some conditions known to mimic psychiatric illness, intravenous amylobarbitone may produce mental clearing despite an organic aetiology (Lampke, 1982). In addition, clinicians have commented on the significant incidence of organic illness in patients with supposed 'hysterical' disorders (Marsden, 1986).

One further area of use for amylobarbitone is in the interviewing of inaccessible or unresponsive patients. Catatonic patients may exhibit a dramatic if temporary reversal of their symptoms (Stevens \& Derbyshire, 1958), while mute or stuporous patients may begin to talk (Altshuler et al. 1986), thus allowing some assessment of their underlying mental states. 
In Britain patients detained under the Mental Health Act (1983) present a particular area of concern. At present, if the intentions of the interview are diagnostic then the consent of the patient must be gained, as investigations are not covered by the act (Everall, 1987). If the intended use is therapeutic then the barbiturate might be given as 'medicine' (as outlined under 'consent to treatment'). The onus is on the Responsible Medical Officer to state his clinical intent in a written management plan.

In many ways this is a technique that has been unable to shake itself free from its own history and associated mythology. Certainly the barbiturate-assisted interview can never replace a thorough knowledge of the many conditions that may mimic psychiatric illness. Likewise, it can never replace a rational and informed approach to the clinical interview and subsequent investigations. Nevertheless, perhaps the time is right for a careful and controlled reassessment of its place in clinical practice. If used with fore-thought the barbiturate-assisted interview may represent a valuable aid to diagnosis.

M. PATRICK AND R. HOWELLS

\section{REFERENCES}

Altshuler, L. L., Cummings, J. L. \& Mills, J. D. (1986). Mutism: review, diagnosis, and report of 22 cases. American Journal of Psichiatry 143, $1409 \cdot 1414$.

Bleckwenn, W. J. (1930a). Production of sleep and rest in psychotic cases. Archives of Neurology and Psychiatry 24, 365-372.

Bleckwenn. W. J. $(1930 b)$. Narcosis as therapy in neuropsychiatric conditions. Journal of the American Medical Association 95, 11681171

Breuer, J. \& Freud, S. (1955). Studies in hysteria 1893-95. In Complete' Psychological W'orks of Sigmund Freud: standard edition, vol. II, (ed. J. Strachey). Hogarth Press: London.

Bronner. A. (1955). The role of sodium amytal in psychotherapy and diagnosis. American Journal of Psychotherapy 9, 234-242.

Brown. D. \& Pedder. J. (1979). Introduction to Psychotherapy. Tavistock: London.

Dysken, M. W., Chang, S. S., Casper, R. C. \& Davis, J. M. (1979). Barbiturate-facilitated interviewing. Biological Psychiatry 14, 421432.

Ellenberger, H. F. (1970). The Discovery of the Unconscious. Allen Lane/Penguin Press: London.

Everall, 1. (1987). Consent to investigation (letter). British Journal of Pspichiatry 151, 869870.

Griesinger, W. (1867). Mental Pathology and Therapeutics (1861). (Translation: C. L. Robertson and J. Rutherford.) The New Sydenham Society: London.

Grinker, R. R. (1944). Treatment of war neuroses. Journal of the American Medical Association 126, 142145

Hadfield, J. A. (1942). War neurosis: a year in a neuropathic hospitul. British Medic.d Journal i, 320.323

Hoch. P. H. (1946). The piesent state of narco-diagnosis and therapy. Journal of Nervous and Mental Disorders 103, 248259.

Horsley, J. S. (1936). Narco-analysis. Journal of Mental Science 82 , $416 \quad 422$.

Kläsi S. (1922). Über die therapeutische Anwendung des Danerschlafes mittels Somnifens bei Schizophrenen. Zeitschriff für der gesiche' Neturologit' und Psychiatrit 74, 557.
Lambert, C. \& Rees, W. L. (1944). Intravenous barbiturates in the treatment of hysteria. British Medical Journal ii, 7073

Lampke, R. S. (1982). Interviewing with intravenous drugs. Journal of Clinical Psychiatry 43, 344.

Lewis, A. J. (1941). Mental disturbances of war. Medical Anmual (ed. H. Tidy and A. Short), pp. 270. 274. John Wright: Bristol.

Lindemann, E. (1932). Psychological changes in normal and abnormal individuals under the influence of sodium amytal. American Journal of Psychiatry 88, 1083-1091.

Marsden, C. D. (1986). Hysteria a neurologist's view. Psychological Medicine 16, 277-288.

Naples, M. \& Hackett, T. P. (1978). The amytal interview: history and current uses. Psychosomatics 19,98 105.

Perry, J. C. \& Jacobs, D. (1982). Overview: clinical applications of the amytal interview in psychiatric emergency settings. American Journal of Psychiarry 139, 552 -559.

Sargant, W. \& Slater, E. (1940). Acute war neuroses. Lancet ii, 13.

Schonle, H. A. \& Moment, A. (1923). Some new hypnotics of the barbituric acid series. Journal of the American Chemical Society 45 , 243-249.

Snow, S. S. \& Wells, C. E. (1981). Case studies in neuropsychiatry: diagnosis and treatment of coexistent dementia and depression. Journal of Clinical Psychiatry 42, 439 44I.

Stevens, J. M. \& Derbyshire, A. J. (1958). Shifts along the alertrepose continuum during remission of catatonic stupor with amobarbital. Psychosomatic Medicine 20, 99107.

Strachey, J. (1934). The nature of the therapeutic action of psychoanalysis. International Journal of Psycho-Analysis 15, 127159.

Tilkin, L. (1949). The present status of narcosynthesis using sodium pentothal and sodium amytal. Diseases of the Nervous System 10. $215-218$.

Ward, N. G., Rowlett, D. B. \& Burke, P. (1978). Sodium amylobarbitone in the differential diagnosis of confusion. American Journal of Psychiatry 135, 7578.

Weinstein, E. A., Kahn, R. L., Sugarman, L. A. \& Maliz, S. (1954). Serial administration of the 'amytal test' for brain disease. Its diagnostic and prognostic value. Archives of Neurology and Psychiatry 71, 217226 